\title{
Immunohistochemial evaluation of sarcoglycans and integrins in gingival epithelium of multiple myeloma patients with bisphosphonate-induced osteonecrosis of the jaw
}

\author{
ENRICO NASTRO SINISCALCHI ${ }^{1}$, GIUSEPPINA CUTRONEO ${ }^{2}$, LUCIANO CATALFAMO ${ }^{1}$, \\ GIUSEPPE SANTORO ${ }^{2}$, ALESSANDRO ALLEGRA $^{3}$, GIACOMO OTERI ${ }^{4}$, DOMENICO CICCIÙ $^{4}$ \\ ANDREA ALONCI $^{3}$, GIUSEPPA PENNA ${ }^{3}$, CATERINA MUSOLINO ${ }^{3}$, FRANCESCO SAVERIO DE PONTE ${ }^{1}$, \\ GIUSEPPE ANASTASI ${ }^{2}$ and ANGELO FAVALORO ${ }^{2}$ \\ ${ }^{1}$ Division of Maxillofacial Surgery, ${ }^{2}$ Department of Biomorphology and Biotechnologies, ${ }^{3}$ Division of Hematology, \\ ${ }^{4}$ Department of Dentistry, University of Messina, Messina, Italy
}

Received December 10, 2009; Accepted January 28, 2010

DOI: 10.3892/or_00000837

\begin{abstract}
Osteonecrosis of the jaw (ONJ) is an adverse outcome associated to bisphosphonate treatment. However, it is not known whether the ONJ lesion originates in the bone, or whether it may initiate in the oral mucosa. The aim of our study was to evaluate the pattern of basal lamina of oral mucosa after bisphosphonate administration and to analyze the structural damage of the mucosa in ONJ patients, and in subjects treated with bisphosphonates without osteonecrosis. By immunohistochemistry, we evaluated changes in basement membrane by expression of signalling proteins, laminin, and type IV collagen. All tested proteins were almost absent in basal lamina and mucosa of subjects treated with bisphosphonates without osteonecrosis, whereas in mucosa of patients with ONJ, they showed a clearly detectable pattern of the same proteins, specifically in basal lamina, but less in comparison to control samples. Moreover, in pathological mucosa, the clearly detectable staining pattern for VEGF indicated a massive neoangiogenesis. Bisphosphonates induce changes in expression of proteins also in oral mucosa. The increase of these proteins in basal lamina, and the neoangiogenesis, concomitant with formation of the lesion, could indicate a compensative behaviour in the remodelling of the gingival mucosa in order to restore the epithelial architecture.
\end{abstract}

Correspondence to: Dr Angelo Favaloro, Università degli Studi di Messina, Dipartimento di Biomorfologia e Biotecnologie, Policlinico Universitario, Torre Biologica, Via C. Valeria, I-98125, Messina, Italy

E-mail: angelo.favaloro@unime.it

Key words: bisphosphonates, multiple myeloma, osteonecrosis, basement membrane, signalling proteins

\section{Introduction}

Bisphosphonates (BPs) are the current standard care for preventing skeletal related events. Since 2003, numerous reports of bisphosphonate-induced osteonecrosis of the Jaws (ONJ) have appeared in literature (1). Several theories have been proposed regarding the pathoetiology of ONJ, e.g. that necrosis is related to an over-suppression of bone turnover by BPs (2) or that BPs decrease angiogenesis $(3,4)$.

Different definitions for ONJ have been proposed and all include exposure of maxillary or mandibular bone, but a breech in the oral mucosa is an absolute requirement. At the present time it is in fact not definitively known whether the ONJ lesion originates in the bone, or whether it may initiate in the mucosa (5).

However, toxicity of BPs to gastric and intestinal mucosal cells has been documented, and the mechanism of damage was independent of microvascular injury, possibly due to disruption of surface active phospholipids within the mucosal layer (6). Twiss et al (7) observed that, in presence of calcium, pamidronate forms insoluble complexes that deposit on the cell surface, exposing gastric mucosa to locally increased and cytotoxic concentrations of the drug $(7,8)$; while Suri et al (9) postulated that the toxic effects on intestinal cells are related to disruption of the mevalonate pathway, which reduces production of cholesterol precursors and interferes with cell membrane biosynthesis.

Although several studies have been carried out on these drugs data are almost absent on structural and proteic modifications that they cause in the oral mucosa. On these basis, we evaluated changes in localization and expression of proteins which play a key role in the maintenance of cellular viability and signalling i.e. vinculin-talin-integrin system and sarcoglycan sub-complex, and in the integrity of basement membrane i.e. laminin, and type IV collagen. Moreover, in order to verify the behaviour of the vascular component, VEGF was also tested.

Basement membranes are thin, specialized extracellular matrices that are important for providing mechanical stability 
to tissue and also provide signals that influence cellular polarity and guide cell migration (10). The extracellular matrix molecule laminin is a large heterodimeric glycoprotein and it is required for basement membrane architecture, providing mechanical support to adjacent cells $(11,12)$.

The vinculin-talin-integrin system constitutes a well known protein machinery which in skeletal muscle fibers forms the costameres (13-17). Vinculin head is known to bind to $\alpha$-actin and talin, whereas vinculin tail is known to bind to paxillin, F-actin and phosphatidylinositol 4,5 bisphosphate (18).

Integrins are transmembrane $\alpha / \beta$ heterodimers that can bind to many extracellular matrix molecules. Integrins are important for cell adhesion and migration, and can have roles in matrix assembly and remodelling (19). The vinculintalin-integrin system is present in numerous tissue and it has the characteristics of atypical focal contacts, binding only intermediate filaments and not thin filaments (20-24), and integrins are its transmembrane part.

The $\alpha 7 \mathrm{~B}$ and $\mathrm{B1D}$ are the most common integrins found in adult skeletal and smooth muscle $(25,26)$; however, we tested these isoforms in gingival mucosa in order to study their behaviour in vascular structures during ONJ. All integrin isoforms are involved in a myriad of biological processes such as haemostasis, immune response, wound healing, angiogenesis, embryogenesis, and tumorigenesis $(22,27)$.

Similarly to the vinculin-talin-integrin system, the sarcoglycan sub-complex (SGC) represents a system that plays an important role in cell-cell binding and in cell viability in many cellular types (28). In particular, the SGC, composed of six proteins ( $\alpha-, \beta_{-}^{-}, \gamma^{-}, \delta_{-}^{-}, \varepsilon^{-}$, and $\zeta_{\text {-sarcoglycan })}$ stabilizes the cell membrane during cellular activity $(29,30)$. It was demonstrated that $\alpha$ - and $\gamma$-sarcoglycan are expressed exclusively in skeletal and cardiac muscle, whereas $\beta$ - and $\delta$ sarcoglycans are more widely expressed (31).

Type IV collagen polymers is though to be key structural element of the basement membrane and is usually accompanied by other glycoproteins.

Our aim was to characterize the distribution and expression of different mucosal proteins after bisphosphonate administration and to evaluate the structural damage of the mucosa in ONJ patients, using immunohistochemical techniques.

\section{Materials and methods}

Patients. Samples of human gingival epithelium were obtained from 10 patients treated with bisphosphonate which did not show ONJ, and from 10 patients treated with bisphosphonates affected by ONJ. These samples were compared with oral mucosa of 10 control subjects who had undergone oral procedures for other reasons. The age of the patients ranged between 30 and 81 years and all gave their informed consent.

The procedures followed were in accordance with the principles outlined in the Helsinki Declaration of 1975.

Patients treated with bisphosphonates without ONJ (4 females and 6 males; median age $72 \pm 11$ years) were affected by multiple myeloma (the paraprotein heavy chain was IgG in all patients; 5 patients were in stage II and 5 in stage III according to the Durie Salmon classification). They were treated with zoledronate ( $4 \mathrm{mg}$ i.v. once a month). The duration from first use of the drug was $36 \pm 12.3$ months. In this group biopsy was made the day before the last administration of bisphosphonates.

In ONJ patients last bisphosphonate administration was made 2-10 days before the biopsy was performed. The patients of this group were 5 females, 5 males; median age $70.1 \pm 12$ years. Four patients were in stage II and 6 patients in stage III according to the Durie Salmon classification. The paraprotein heavy chain was IgG in all patients. All patients presented with an area of exposed bone and pain or swelling. The mandible and maxilla were the only bones involved in the exposure. Three cases of exposure occurred exclusively in the mandible, 3 exclusively in the maxilla and 4 simultaneously in the mandible and maxilla. The posterior mandible in the area of the molars was the most common site of exposure $(n=3)$. All cases occurred after dental disease, oral surgical treatment or a traumatic injury of the oral mucosa by inadequate dentures. They received zoledronate (4 mg i.v. once every 3 weeks or once a month). The time from the first use of the drug to the first recognition of exposed bone was $33 \pm 15.1$ months.

None of the studied patients had received chemotherapy at the time of biopsy. Patients with acute or chronic infections, diabetes, liver, kidney and inflammatory diseases were excluded from the study.

Specimens of oral mucosa were taken during surgical procedures, consisting of the removal of the sequestred bone, in patients affected by ONJ.

In the other groups, biopsies of crestal mucosa were performed during several oral surgical procedures (i.e. dental extractions, and implantology). No adrenaline was used for local anesthesia.

Immunohistochemistry. The specimens were analyzed using immunohistochemistry. Biopsies were fixed in $3 \%$ paraformaldehyde in $0.2 \mathrm{M}$ phosphate buffer, $\mathrm{pH} 7.4$, for $2 \mathrm{~h}$ at room temperature. They were then washed extensively with $0.2 \mathrm{M}$ phosphate buffer, $\mathrm{pH} 7.4$, and then with phosphatebuffered saline (PBS), containing 12 and $18 \%$ sucrose. The samples were snap-frozen in liquid nitrogen and $20 \mu \mathrm{m}$ sections were prepared in a cryostat for their use in a protocol for immunofluorescence. The sections were placed on glass slides that were coated with $0.5 \%$ gelatin and $0.005 \%$ chromium potassium sulphate.

To block non-specific binding sites and to permeabilize the membranes, the sections were preincubated with $1 \%$ bovine serum albumin (BSA), $0.3 \%$ Triton X-100 in PBS at room temperature for $15 \mathrm{~min}$. Finally, the sections were incubated with primary antibodies.

The following antibodies for triple fluorescence were used: anti- $\alpha$-sarcoglycan diluted 1:100, anti- $\beta$-sarcoglycan diluted 1:200, anti- $\gamma$-sarcoglycan diluted $1: 100$, anti- $\delta$ -

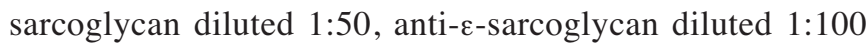
(all from Novocastra Laboratories, Newcastle upon Tyne, UK); anti-vinculin diluted 1:100, and anti-type IV collagen diluted 1:100 (both from Sigma Chemicals, St. Louis, MO); anti-VEGF diluted 1:100 (Jackson ImmunoResearch Laboratories, West Grove, PA); anti- $\alpha 7 \mathrm{~B}$-integrin diluted 

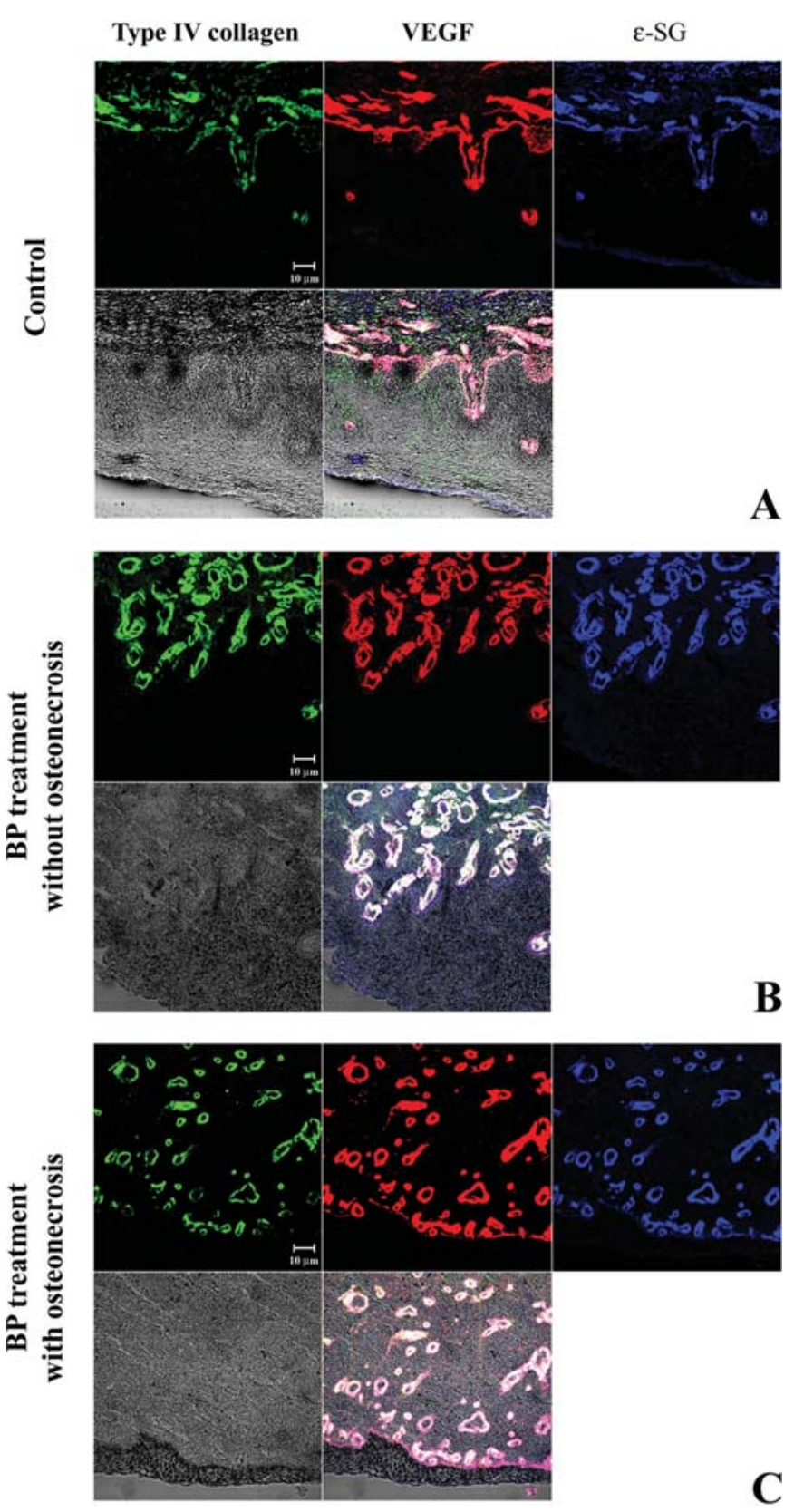

Figure 1. Compound panel showing immunohistochemical findings in human gingival epithelium immunolabeled with a triple immunofluorescence reaction, with type IV collagen (green channel), VEGF (red channel) and $\varepsilon$-sarcoglycan (blue channel). The gingival epithelium was analyzed in control subjects (A), in subjects treated with BPs showing no ONJ (B), and in subjects treated with BPs who showed ONJ (C). For each reaction it is possible to analyze the single proteins separately, the transmitted light and the merge between all channels. Almost complete absence of tested proteins on basal lamina was observed in subjects without ONJ, and a new increase of the same proteins on basal lamina in subjects with ONJ. Furthermore, qualitatively and quantitatively increasing neoangiogenesis was evident below the basal lamina.

1:50, anti- $\beta D$-integrin diluted 1:50 (synthetic peptides from the $\mathrm{COOH}$ terminal region; kindly provided by the laboratory of Professor Tarone, University of Torino). In all reactions, TRITC-conjugated IgG anti-rabbit (red channel), FITCconjugated IgG anti-mouse (green channel), and Texas Redconjugated IgG anti-goat (blue channel), all from Jackson ImmunoResearch Laboratories, were used respectively.
Slides were finally washed in PBS and sealed with mounting medium. To provide a control for non-specific immunostaining of sections we performed triple immunofluorescence reactions using secondary antibodies only.

The sections were then analyzed and images acquired using a Zeiss LSM 5 DUO confocal laser scanning microscope by META module. All images were digitalized at a resolution of 8 bits into an array of 2048x2048 pixels. Optical sections of fluorescent specimens were obtained using a HeNe laser (wavelength $=543 \mathrm{~nm}$ ) and an Argon laser (wavelength $=458 \mathrm{~nm}$ ) at a 1 -min 2-sec scanning speed with up to 8 averages; $1.50 \mu \mathrm{m}$-thick sections were obtained using a pinhole of 250 . Contrast and brightness were established by examining the most brightly labelled pixels and choosing the settings that allowed clear visualization of the structural details while keeping the pixel intensity at its highest ( 200). Each image was acquired within $62 \mathrm{sec}$, in order to minimize photodegradation. Digital images were cropped and the figure montage prepared using Adobe Photoshop 7.0.

\section{Results}

To design a targeting model to better define the role of sarcoglycans, integrins, and matrix proteins in oral mucosa, we analyzed the immunofluorescence of these proteins in samples treated with bisphosphonates of subjects that did not show osteonecrosis; secondary, we studied samples of oral mucosa in patients affected by ONJ. Each group was, finally, compared with control samples.

In order to also study the colocalization of tested proteins, we performed triple immunofluorescence reactions; then, in all observations we applied the 'split' function, that permits to analyze the three fluorescences and transmitted light, separately, and the merge between all channels.

The triple immunofluorescence reaction, performed between type IV collagen (green channel), VEGF (red channel), and $\varepsilon$-sarcoglycan (blue channel) antibodies, in control subjects, showed a clear normal pattern of all proteins in basement membrane, which was perfectly delineated, and some vascular structures. The fluorescence analysis of the same proteins in samples treated with bisphosphonates, not pathological for ONJ, showed an almost absent protein staining pattern in the basal lamina. These proteins showed clearly detectable staining in the vascular structures. In the sections of subjects treated with bisphosphonates that showed osteonecrosis, we observed an increase of protein staining patterns on basal lamina and, contemporarily, qualitative and quantitative increase of vessels below the basal lamina (Fig. 1).

Triple fluorescence reaction performed with laminin (green channel), ß1D-integrin (red channel), and B-sarcoglycan (blue channel) in control subject showed normal staining patterns of all proteins with a clear fluorescence on basal lamina. The same proteins in samples treated with bisphosphonates of subjects that showed no lesions, basal lamina fluorescence is absent whereas the vessels are clearly detectable. In the samples of subjects treated with bisphosphonates that showed osteonecrosis, it was possible to highlight new increase of staining patterns on basal lamina and a massive increase of vascular structures (Fig. 2). 

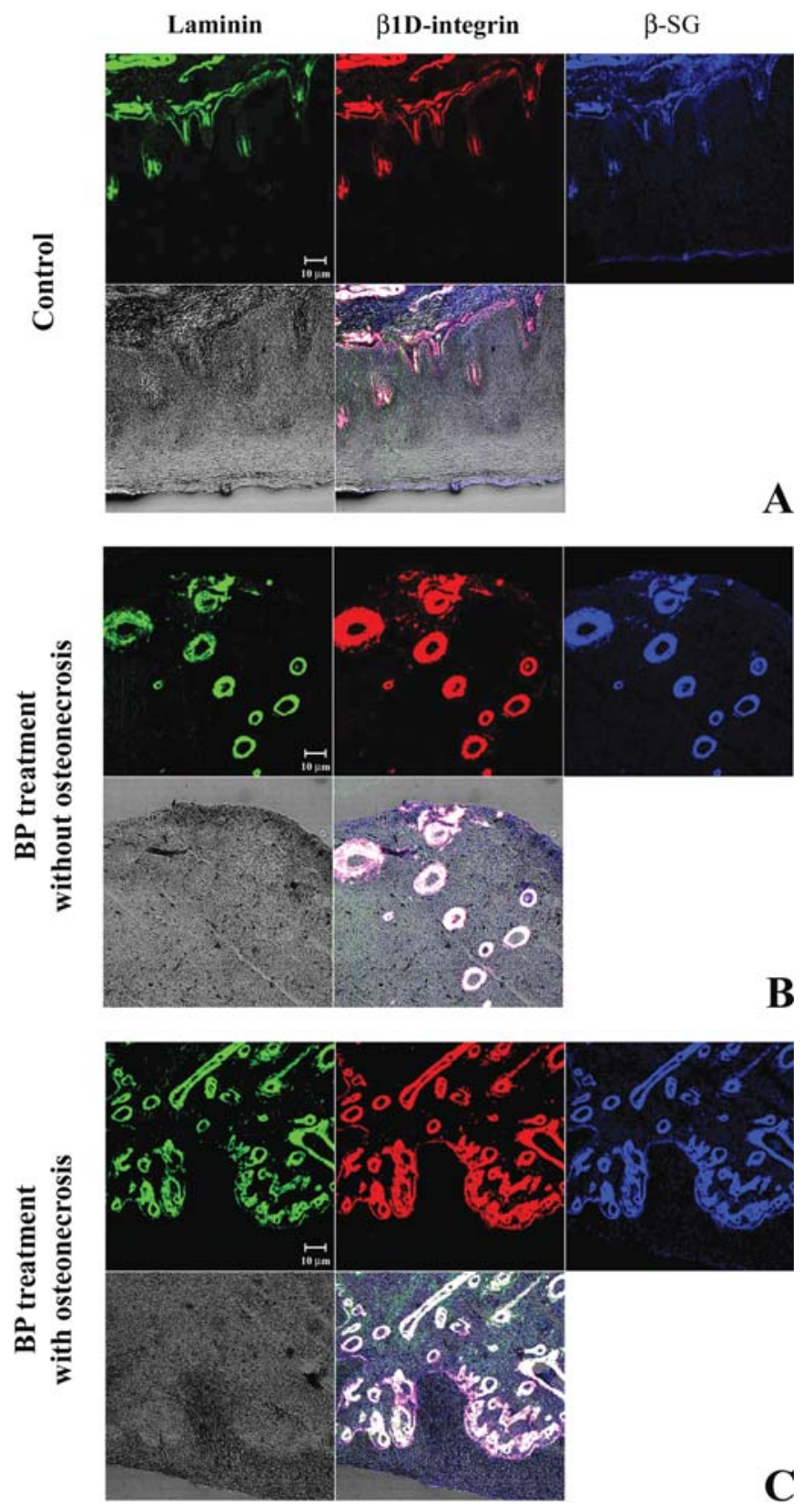

Figure 2. Compound panel showing immunohistochemical findings in human gingival epithelium immunolabeled by a triple immunofluorescence reaction, with laminin (green channel), B1D-integrin (red channel) and $B$-sarcoglycan (blue channel). The gingival epithelium was analyzed in control subjects (A), in subjects treated with BPs who showed no ONJ (B), and in subjects treated with BPs who showed ONJ (C). For each reaction it is possible to analyze the single proteins separately, the transmitted light and the merge between all channels. In subjects without ONJ, the almost complete absence of tested proteins in the basal lamina with contemporary increase of vessels was seen. In subjects with ONJ, a new increase of the same proteins on basal lamina and a further qualitatively and quantitatively increasing neoangiogenesis below the basal lamina were visible.

Triple fluorescence reactions using vinculin (green channel), $\alpha 7 \mathrm{~B}$-integrin (red channel), and $\gamma$-sarcoglycan (blue channel) antibodies showed the same behaviour of other proteins. In particular, in the control sample, a clear staining pattern of all proteins is detectable in the basal
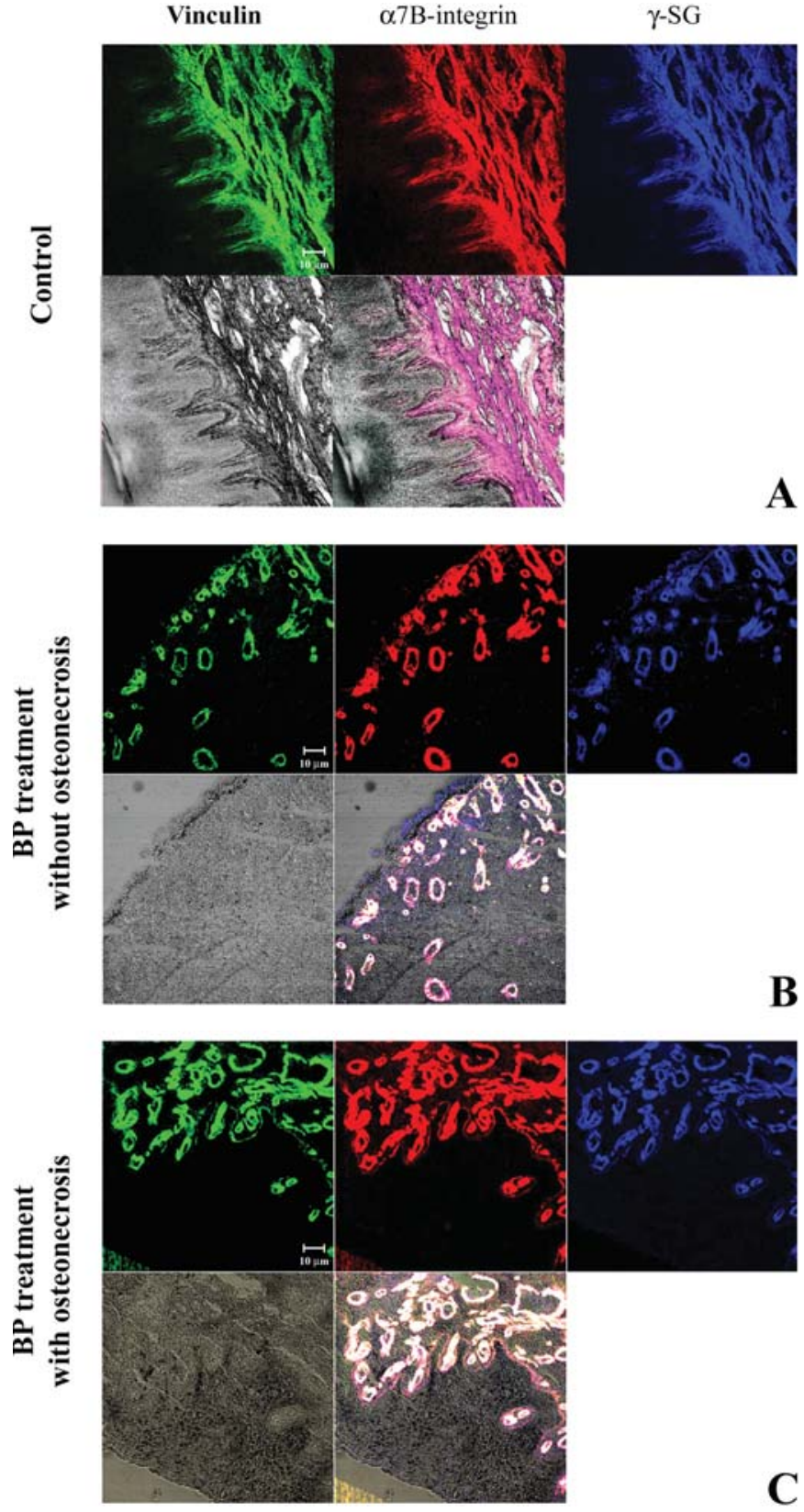

Figure 3. Compound panel showing immunohistochemical findings in human gingival epithelium immunolabeled by a triple immunofluorescence reaction, with vinculin (green channel), $\alpha 7 \mathrm{~B}$-integrin (red channel) and $\gamma$-sarcoglycan (blue channel). The gingival epithelium was analyzed in control subjects (A), in subjects treated with BPs who showed no ONJ (B), and in subjects treated with BPs who showed ONJ (C). For each reaction it is possible to analyze the single proteins separately, the transmitted light and the merge between all channels. Our results showed in subjects without ONJ, an absence of tested proteins in the basal lamina, while the vascular structures appeared increased. In subjects with ONJ, an increase of the same proteins on basal lamina and a massive increase of neoangiogenesis below the basal lamina were observed.

lamina, and a decrease, near absence, of the same proteins in basal lamina of samples treated with bisphosphonates without lesion with increase of vascular structures; finally, in the samples treated with bisphosphonates showing lesions, an increase of staining pattern both in the basal lamina and in vessels was detectable (Fig. 3). 


\section{Discussion}

The basement membrane is a dynamic structure that undergoes quantitative and qualitative changes during diseases, being continuously remodelled by glycoprotein rupture and synthesis. These processes are important in inflammation and tissue repair, as the membrane becomes fragmented to allow inflammatory cell entry and exit. Such fragmentation needs to be orderly, rapidly and accurately repaired.

It is more than a support structure, and it is also involved in signalling during angiogenesis, since various angiogenesis-modulating molecules, growth factors and cytokines are stored in the basal membrane to be released and activated when the basal membrane is breached (32). An emerging paradigm is that the architecture itself transmits information to cells, through mechanisms such as matrix rigidity, spatial arrangement of cell receptors, and tension exerted between matrix and receptor $(33,34)$. The adverse effects of BPs on oral epithelium may play a critical role in the onset of ONJ.

Landesberg et al (35) proposed that oral epithelial cells are subjected to local increases in BPs concentration after a traumatic event, and that the presence of BPs may inhibit epithelial wound healing, contributing to persistent exposure of underlying bone and development of ONJ. BP pre-treatment of oral mucosal cells inhibits proliferation and this inhibition is not due to cellular apoptosis (35).

Although numerous studies have been carried out on the behaviour of these proteins in most tissues, scarce data exist on their expression on oral mucosa in normal and in pathological conditions. However, it is well known that cells with disrupted talin function fail to form focal adhesions and exhibit spreading defects, whereas cells with vinculin disruption can form focal adhesions, but display reduced ability to spread and increase cell motility $(36,37)$.

Here we used immunofluorescence techniques to analyze any proteins of vinculin-talin-integrin system and DGC, and moreover type IV collagen and laminin, in oral mucosa treated with bisphosphonates to evidence their role in these conditions.

In the present study, analyzing human gingival mucosa of subjects in treatment with bisphosphonates, for the first time, our data showed, clearly, that all tested proteins are almost absent, in basal lamina and oral mucosa of subjects treated with BPs but without osteonecrosis, whereas in oral mucosa with necrosis, patients showed a clearly detectable staining pattern of the same proteins, specifically in basal lamina, but less in comparison to control samples.

Moreover, by VEGF immunofluorescence analysis, in oral mucosa with lesion, a massive neoangiogenesis was clearly detectable. This is an unexpected finding as in previous studies we demonstrated the possibility that BPs could have a suppressive effect on angiogenesis $(4,38)$. However, BPs could exert a different action on bone and mucosal tissue.

These data, for the first time, demonstrated that the tested proteins showed a key role in cellular signalling between cell and extracellular matrix. In particular, the increase of these proteins in basal lamina, concomitant with formation of the lesion, could indicate a compensative behaviour in the remodelling of the gingival mucosa in order to restore the epithelial architecture, and then to resume the signalling pathway of the cells. The neoangiogenesis, high-lighted by an increase of immunostaining patterns of two tested integrins and of VEGF, showed an unexpected feature during bisphosphonate treatment, confirming this compensative role of tested proteins.

Additional experiments performed to better clarify the action of BPs on oral mucosa should be made as ONJ lesion may initiate in the oral mucosa, and it is well known that human gingival fibroblast and human periodontal ligament cells might also have a role in osteoclastogenesis though the expression of receptor activator of nuclear factor kappa B ligand (RANKL) on their cell surface (39). Moreover, impact of BPs on mucosal cells could be useful to chose the most appropriate therapy as it was demonstrated that Pamidronate is not able to promote death of oral mucosal cells, although at BP doses greater than $0.1 \mathrm{mM}$ there is a toxic effect that results in the detachment of the adherent cells.

Further studies on mucosal damage by BPs could indicate new paths of investigation leading to an improved understanding of ONJ.

\section{References}

1. Hoff AO, Toth BB, Altundag K, Johnson MM, Warneke CL, $\mathrm{Hu}$ M, Nooka A, Sayegh G, Guarneri V, Desrouleaux K, Cui J, Adamus A, Gagel RF and Hortobagyi GN: Frequency and risk factors associated with osteonecrosis of the jaw in cancer patients treated with intravenous bisphosphonates. J Bone Miner Res 23: 826-836, 2008

2. Marx RE, Fortin M and Broumand V: Bisphosphonate-induced exposed bone (osteonecrosis/osteopetrosis) of the jaws: risk factors, recognition, prevention and treatment. J Oral Maxillofacial Surg 63: 1567-1575, 2005.

3. Bezzi M, Hasmim M, Bieler G, Dormond O and Ruegg C: Zoledronate sensitizes endothelial cells to tumor necrosis factorinduced programmed cell death: evidence for the suppression of sustained activation of focal adhesion kinase and protein kinase B/Akt. J Biol Chem 278: 43603-43614, 2003.

4. Allegra A, Oteri G, Nastro E, Alonci A, Bellomo G, Del Fabro V, Quartarone E, Alati C, De Ponte FS, Cicciù D and Musolino C: Patients with bisphosphonate-associated osteonecrosis of the jaw have reduced circulating endothelial cells. Hematol Oncol 25: 164-169, 2007

5. Khosla S, Burr D, Cauley J, Dempster DW, Ebeling PR, Felsenberg D, Gagel RF, Gilsanz V, Guise T, Koka S, McCauley LK, McGowan J, McKee MD, Mohla S, Pendrys DG, Raisz LG, Ruggiero SL, Shafer DM, Shum L, Silverman SL, Van Poznak CH, Watts N, Woo SB and Shane E: Bisphosphonate-associated osteonecrosis of the jaw: report of a Task Force of the American Society for Bone and Mineral Research. J Bone Miner Res 22: 1479-1491, 2007.

6. Wallace JL, Dicay M, McKnight W, Bastaki S and Blank MA: $\mathrm{N}$-bisphosphonates cause gastric epithelial injury independent of effects on the microcirculation. Alimen Pharmacol Ther 13: $1675-1682,1999$.

7. Twiss IM, Pas O, Rampkoopmanscap W, den Harigh J and Vermeij P: The effects of nitrogen-containing bisphosphonates on human epithelial (Caco-2) cells, an in vitro model for intestinal epithelium. J Bone Miner Res 14: 784-791, 1992.

8. Twiss IM, de Water R, den Harigh J, Sparidans R, RampKoopmanschap W, Brill H, Wijdeveld M and Vermeij P: Cytotoxic effects of pamidronate on monolayers of human intestinal epithelial (Caco-2) cells and its epithelial transport. J Pharm Sci 83: 699-703, 1999.

9. Suri S, Monkkonen J, Taskinen M, Pesonen J, Blank MA, Phipps RJ and Rogers MJ: Nitrogen-containing bisphosphonates induce apoptosis of Caco-2 cells in vitro by inhibiting the mevalonate pathway: a model of bisphosphonate-induced gastrointestinal toxicity. Bone 29: 336-343, 2001.

10. Alberts B: Juncoes celulares, adesao cellular e a matrix extracellular. In: Artes Medicas. 3 edit. (RS) Porto Alegre, 1997. 
11. Huang CC, Hall DH, Hedgecock EM, Kao G, Karantza V, Vogel BE, Hutter H, Chisholm AD, Yurchenco PD and Wadsworth WG: Laminin (alpha) subunits and their role in C elegans development. Development 130: 3343-3358, 2003.

12. Colognato H, Winkelmann DA and Yurchenco PD: Laminin polymerization induces a receptor-cytoskeleton network. J Cell Biol 145: 619-631, 1999.

13. Xing B, Jedsayanmata A and Lam SCT: Localization of an integrin binding site to the $\mathrm{C}$ terminus of talin. J Biol Chem 276: 44373-44378, 2001

14. Gingras AR, Ziegler WH, Frank R, Barsukov IL, Roberts GC, Critchley and Emsley J: Mapping and consensus sequence identification for multiple vinculin binding sites within the talin rod. J Biol Chem 280: 37217-3724, 2005.

15. Trimarchi F, Favaloro A, Fulle S, Magaudda L, Puglielli C and Di Mauro D: Culture of human skeletal muscle myoblasts: timing appearance and localization of dystrophin-glycoprotein complex and vinculin-talin-integrin complex. Cells Tissues Organs 183: $87-98,2006$

16. Anastasi G, Cutroneo G, Pisani A, Bruschetta D, Milardi D, Princi P, Gucciardi PG, Bramanti P, Soscia L and Favaloro A: Can scanning near-field optical microscopy be compared with confocal laser scanning microscopy? a preliminary study on alphasarcoglycan and beta1D-integrin in human skeletal muscle. J Microsc 228: 322-329, 2007.

17. Anastasi G, Cutroneo G, Santoro G, Arco A, Rizzo G, Bramanti P, Rinaldi C, Sidoti A, Amato A and Favaloro A: Costameric proteins in human skeletal muscle during muscular inactivity. J Anat 213: 284-295, 2008

18. Winkler JH, Lunsdorf H and Jockusch BM: The ultrastructure of chicken gizzard vinculin as visualized by high-resolution electron microscopy. J Struct Biol 116: 270-177, 1996.

19. Gettner SN, Kenyon C and Reichardt LF: Characterization of beta pat-3 heterodimers, a family of essential integrin receptors in C. elegans. J Cell Biol 129: 1127-1141, 1995.

20. Kramer RH, Vu MP, Cheng YF, Ramos DM, Timpl R and Waleh N: Laminin binding integrin alpha7/beta1: functional characteristic and expression in normal and malignant melanocytes. Cell Regul 2: 805-817, 1991.

21. Danowski BA, Imanaka-Yoshida K, Sanger JM and Sanger JW: Costameres are sites of force transmission to the substratum in adult rat cardiomyocytes. J Cell Biol 118: 1411-1420, 1992.

22. Hynes RO: Integrins: versatility, modulation and signalling in cell adhesion. Cell 69: 11-25, 1992

23. Schwartz MA, Schaller MD and Ginsberg MH: Integrins: emerging paradigms of signal transduction. Annu Rev Cell Dev Biol 11: 549-599, 1995.

24. Yamada KM and Miyamoto S: Integrin transmembrane signalling and cytoskeleton control. Curr Opin Cell Biol 7: 681-689, 1995

25. Belkin AM, Zhidkova NI, Balzac F, Altruda F, Tomatis D, Maier A, Tarone G, Koteliansky VE and Burridge K: B1D integrin displaces the $\mathrm{B} 1 \mathrm{~A}$ isoform in striated muscle: localization at junctional structures and signaling potential in non-muscle cells. J Cell Biol 132: 211-226, 1996
26. Belkin AM, Retta SF, Pletjushkina OY, Balzac F, Silengo L, Fassler R, Koteliansky VE, Burridge K and Tarone G: Muscle $\beta 1 D$ integrin reinforces the cytoskeleton-matrix link: modulation of integrin adhesive function by alternative splicing. J Cell Biol 139: 1583-1595, 1997.

27. Sastry S and Horwitz A: Integrin cytoplasmic domains: mediators of cytoskeletal linkages and extra- and intracellular initiated transmembrane signaling. Curr Opin Cell Biol 5: 819-831, 1993.

28. Anastasi G, Amato A, Tarone G, Vita G, Monici MC, Magaudda L, Brancaccio M, Sidoti A, Trimarchi F, Favaloro A and Cutroneo G: Distribution and localization of vinculin-talin integrin system and dystrophin-glycoprotein complex in human skeletal muscle: immunohistochemical study using confocal laser scanning microscopy. Cells Tissues Organs 175: 151-164, 2003.

29. Ervasti JM, Ohlendieck K, Kahl SD, Gaver MG and Campbell KP: Deficiency of a glycoprotein component of the dystrophin complex in dystrophic muscle. Nature 345: 315-319, 1990.

30. Yoshida M and Ozawa E: Glycoprotein complex anchoring dystrophin to sarcolemma. J Biochem 108: 748-752, 1990.

31. Ettinger AJ, Feng G and Sanes JR: $\varepsilon$-sarcoglycan, a broadly expressed homologue of the gene mutated in limb-girdle muscular dystrophy 2D. J Biol Chem 272: 32534-32538, 1997.

32. Engbring JA and Kleinman HK: The basement membrane matrix in malignancy. J Pathol 200: 465-470, 2003.

33. Stamenovic D, Fredberg JJ, Wang N, Butler JP and Ingber DE: A microstructural approach to cytoskeletal mechanics based on tensegrity. J Theor Biol 181: 125-136, 1996.

34. Ezzell RM, Goldmann WH, Wang N, Parasharama N and Ingber DE: Vinculin promotes cell spreading by mechanically coupling integrins to the cytoskeleton. Exp Cell Res 231: 14-26, 1997.

35. Landesberg R, Cozin M, Cremers S, Woo V, Koustent S and Sinba S: Inhibition of oral mucosal cell wound healing by Bisphosphonates. J Oral Maxillofac Surg 66: 839-847, 2008.

36. Priddle H, Hemmings L, Monkeley S, Woods A, Patel B, Sutton D, Dunn GA, Zicha D and Critchley DR: Disruption of the talin gene compromises focal adhesion assembly in undifferentiated but not differentiated embryonic stem cells. J Cell Biol 142: 1121-1133, 1998

37. Xu WM, Coll JL and Adamson ED: Rescue of the mutant phenotype by reexpression of full-length vinculin in null F9 cells; effects on cell locomotion by domain deleted vinculin. J Cell Sci 111: 1535-1544, 1998.

38. Oteri G, Allegra A, Bellomo G, Alonci A, Nastro E, Penna G, Catalfamo L, Cicciù D, De Ponte FS and Musolino C: Reduced serum levels of Interleukin 17 in patients with osteonecrosis of the jaw in multiple myeloma subjects after bisphosphonates. Cytokine 43: 103-104, 2008.

39. Bertoldo F, Santini D and Lo Cascio V: Bisphosphonates and osteomyelitis of the jaw: a pathogenic puzzle. Nat Clin Pract Oncol 4: 711-721, 2007. 